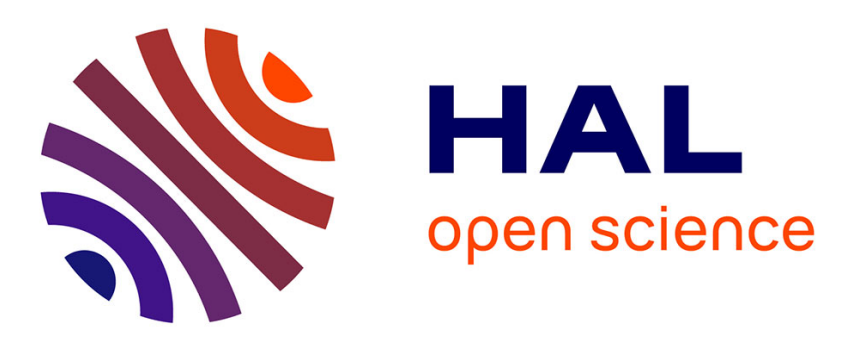

\title{
Improving damping capabilities of composites structures by electroactive films containing piezoelectric and conductive fillers
}

L Quiroga Cortes, Leonardo Sanches, Camille Bessaguet, Mathieu Chevalier, Colette Lacabanne, Eric Dantras, Guilhem Michon

\section{To cite this version:}

L Quiroga Cortes, Leonardo Sanches, Camille Bessaguet, Mathieu Chevalier, Colette Lacabanne, et al.. Improving damping capabilities of composites structures by electroactive films containing piezoelectric and conductive fillers. Smart Materials and Structures, 2021, 30 (8), pp.085008. 10.1088/1361665X/ac0670 . hal-03371154

\section{HAL Id: hal-03371154 \\ https://hal.science/hal-03371154}

Submitted on 8 Oct 2021

HAL is a multi-disciplinary open access archive for the deposit and dissemination of scientific research documents, whether they are published or not. The documents may come from teaching and research institutions in France or abroad, or from public or private research centers.
L'archive ouverte pluridisciplinaire HAL, est destinée au dépôt et à la diffusion de documents scientifiques de niveau recherche, publiés ou non, émanant des établissements d'enseignement et de recherche français ou étrangers, des laboratoires publics ou privés. 


\section{Open Archive Toulouse Archive Ouverte (OATAO)}

OATAO is an open access repository that collects the work of Toulouse researchers and makes it freely available over the web where possible

This is an author's version published in: http://oatao.univ-toulouse.fr/28142

Official URL: https://doi.org/10.1088/1361-665X/ac0670

\section{To cite this version:}

Cortes, L Quiroga and Sanches, Leonardo Chevalier, Mathieu and Lacabanne, Colette $\rightleftharpoons$ and Dantras, Eric Michon, Guilhem Improving damping capabilities of composites structures by electroactive films containing piezoelectric and conductive fillers. (2021) Smart Materials and Structures, 30 (8). 085008. ISSN 0964-1726

Any correspondence concerning this service should be sent to the repository administrator: tech-oatao@listes-diff.inp-toulouse.fr 


\title{
Improving damping capabilities of composites structures by electroactive films containing piezoelectric and conductive fillers
}

\author{
L Quiroga Cortes ${ }^{1}$, L Sanches ${ }^{3}$, C Bessaguet $^{1,2,3}$, M Chevalier $^{1}$, C Lacabanne $^{2}$ (D), \\ E Dantras $^{2, *}$ and G Michon ${ }^{3}$ (i) \\ ${ }^{1}$ Institut de Recherche Technologique (IRT) Saint Exupéry, 3 Rue Tarfaya, CS 44248, 31405 Toulouse \\ Cedex 4, France \\ ${ }^{2}$ CIRIMAT, Physique des polymères, Université de Toulouse, CNRS, UPS, 118 route de Narbonne, \\ 31062 Toulouse Cedex 09, France \\ ${ }^{3}$ Université de Toulouse, ICA, ISAE-SUPAERO, UPS, INSA Toulouse, IMT Albi, CNRS, 3 Rue \\ Caroline Aigle, 31000, Toulouse, France \\ E-mail: guilhem.michon@isae-supaero.fr
}

\begin{abstract}
In this paper, a passive vibration damping concept based on multifunctional materials was studied for thermoplastic composite structures. The synergy between piezoelectric and conductive particles brings a new contribution of energy dissipation based on the local transduction-dissipation phenomenon. While piezoelectric fillers ensure the conversion of mechanical energy into electrical energy (transduction), conductive particles locally dissipate the electric charges created avoiding saturation in the vicinity of piezoelectric particles. Here, the concept has been studied at material and structure scales for laboratory and preindustrial samples in order to bring solid proof of the damping concept. For this purpose, piezoelectric and electrically conductive particles were dispersed into engineering thermoplastics polyamide 12 and poly ether ketone ketone. Damping films were obtained by hot press and embedded in a composite sandwich beam and carbon fiber reinforced polymer (CFRP)-aluminum panels. Dynamic mechanical analysis and vibration tests were performed on bulk nanocomposite samples and in composite sandwich beams. The study of hysteresis loops and frequency response function showed strong nonlinear effects and vibration amplitude decrease up to 50\%. Tests on CFRP-aluminum panels highlighted the structural damping increase demonstrating the potential capacity of this multifunctional material for energy dissipation in typical aerospace structures.
\end{abstract}

Keywords: structural composites, nanocomposites, vibration, piezoelectric fillers, damping

(Some figures may appear in colour only in the online journal) 


\section{Introduction}

Carbon fiber reinforced polymers (CFRPs) are of growing interest for aeronautic and aerospace applications due to their low density and high stiffness. However, their use as structural materials is compromised by their low vibration damping [1]. To improve damping ability in composites structures, current solutions consist in ensuring structure reliability by active and passive control [2-4] and add-on macroscopic elements [5-7] to adapt the dynamic response. Regarding passive solutions the literature reports the integration of viscoelastic layers (elastomer, thermoplastic polymer) between composite plies (elastic layer) [8-10]. The higher the modulus difference between the viscoelastic layer and composite plies, the more energy storage in the viscoelastic layer and damping is achieved [11]. This layer can be integrated in the constrained layer damping configuration or in the patch constrained layer damping to limit the impact on structure mechanical properties [12-16], generally placed at the highest shear stresses area [9].

Moreover, it has already been shown that polymer damping properties can be improved by the introduction of piezoelectric and conductive nanoparticles [17-28]: The synergy of these two particles leads to a new contribution of energy dissipation: the local transduction-dissipation phenomenon (passive solution). Piezoelectric particles ensure mechanic-electric transduction, while conductive particles dissipate electric charges by the Joule effect through the polymer matrix. Indeed, the literature reveals that the introduction of a small quantity of conductive particles in a polymer/piezoelectric nanocomposite leads to a significant increase in damping [26, 29, 30]. In addition, Tanimoto [18] reported damping enhancement by dispersing Lead Zirconate Titanate (PZT) particles at composite interlayers while using conductive carbon fibers to dissipate the electric charges generated by PZT through Joule dissipation. For low fractions of PZT $\left(<8 \mathrm{~g} \mathrm{~m}^{-2}\right)$ [22] damping performance was improved by a factor of 4 compared to the standard composite.

The effect of introducing a polymer matrix filled with piezoelectric and conductive particles as an interlayer film between two elastic layers has recently been studied by Carponcin et al [26]. Here polyamide 11 (PA 11) based nanocomposites containing PZT particles (30 vol.\%) and carbon nanotubes (CNT) (0.2 vol.\%) where constrained between two thin plates of aluminum. Vibration tests revealed a significant increase in damping efficiency through the synergy of the two kinds of particles, where high amplitude modes decrease up to $50 \%$.

In this work poly (ether ketone ketone) (PEKK) and polyamide 12 (PA 12), two thermoplastic polymers, were chosen as host matrices for damping nanocomposites. Sodium niobate $\left(\mathrm{NaNbO}_{3}\right)$ and barium titanate $\left(\mathrm{BaTiO}_{3}\right)$ were used as leadfree submicronic piezoelectric particles while spherical carbon black (CB) and CNT were used as conductive particles. Damping films were embedded in unidirectional (UD) carbon fiber sandwich beams and in CFRP-aluminum panels. Materials were analyzed by dynamical mechanical analysis (DMA) in isothermal and non-isothermal conditions in order to assess energy dissipation. Concerning the sandwich beams and panels, the energy dissipation was measured through quality factors by vibration tests in a wide frequency range. Both, DMA and vibration tests were evaluated for non-poled and poled piezoelectric samples, and later they were compared to evidence the contribution of energy dissipation through the transduction-dissipation concept. Moreover, the influence of sample configuration and experimental parameters on the damping performance is also studied.

Section 2 describes the experimental procedure used to fabricate composite sandwich beams and panels embedded with the damping film, beyond presenting the mechanical and vibrational tests used for characterizing the dynamic strength and damping behavior for each sample. The mechanical properties obtained throughout the extensive tests are assessed and discussed in section 3. Finally, section 4 highlights the main conclusions on the contribution of the transduction-dissipation mechanism achieved by combining conductive and piezoelectric particles.

\section{Experimental set-up}

\subsection{Composite processing}

2.1.1. Laboratory scaled samples: sandwich composite beams. Laboratory scaled nanocomposites were obtained by dispersing sodium niobate $\left(\mathrm{NaNbO}_{3}\right)$ and $\mathrm{CB}$ in PEKK. PEKK KEPSTAN 7003 was supplied by Arkema in powder form in $20 \mu \mathrm{m}$ diameter. $\mathrm{CB}$ was purchased in powder form $\left(d_{50}=6.3 \mu \mathrm{m}\right)$ from Sigma Aldrich. Sodium niobate particles were synthesized through hydrothermal synthesis from niobium pentoxide and concentrated sodium hydroxide precursors [31, 32] in the laboratory facilities. Synthetized particles are cubic shaped and $2-5 \mu \mathrm{m}$ in size. The three elements were mixed, dispersed in ethanol and sonicated to promote homogeneous dispersion. After ethanol evaporation in a rotary evaporator, a homogenous three phase powder was obtained and hot pressed at $360{ }^{\circ} \mathrm{C}$ to obtain nanocomposite films (figure 1(a)): $\mathrm{NaNbO}_{3}$ appears in white unshaped particles while $\mathrm{CB}$ appears with a perfect spherical morphology. Piezo-electrical particles content is $30 \%$ vol.; while conductive fillers is $4 \%$ vol.

Thin films $(200 \mu \mathrm{m})$ were processed and embedded in a composite sandwich beam (figure 1(b)). In this configuration the damping film is placed between two UD tapes of CFRP.

Two different configurations were studied:

- A symmetric configuration for DMA where the nanocomposite film is embedded between two composite plies. Dimensions $(\mathrm{mm}): 50 \times 10 \times 0.5$.

- An asymmetric configuration for vibration tests, where the damping film is integrated between one ply from one side and two plies of CFRP on the other side. Dimensions (mm): $100 \times 20 \times 0.7$.

2.1.2. Preindustrial scaled samples: CFRP-aluminum honeycomb panels. Carbon-fiber aluminum-honeycomb sandwich panels $(500 \mathrm{~mm} \times 500 \mathrm{~mm})$ were elaborated in order 


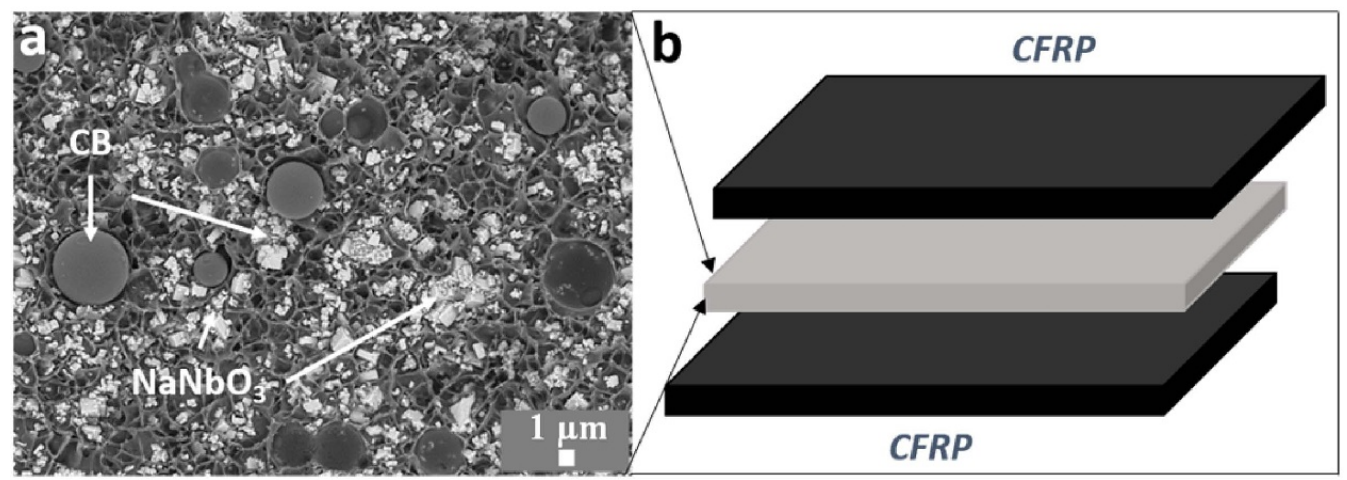

Figure 1. (a) Three phase PEKK/NaNbO $3 / \mathrm{CB}$ nanocomposite film. (b) schematic representation of a constrained damping-layer between thermoplastic composites plies (composite sandwich beam).
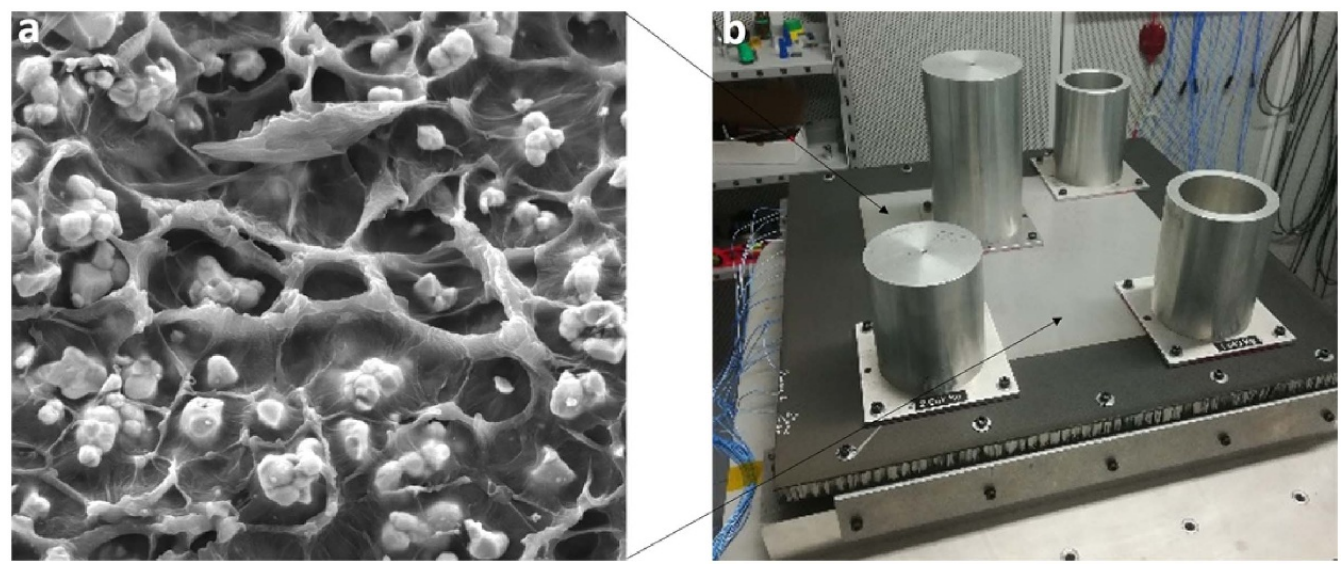

Figure 2. (a) Three phase $\mathrm{PA} / \mathrm{BaTiO}_{3} / \mathrm{CNT}$ nanocomposite film $\left(\mathrm{BaTiO}_{3}\right.$ particles appears in white while NTC are not observed) (b) carbon-fiber aluminum-honeycomb sandwich panel containing the damping-film in the surface as a patch and loaded with masses.

to test the concept in a representative composite structure. For this purpose, commercially available fillers were used to elaborate the damping film: $\mathrm{BaTiO}_{3}$ particles (Sigma Aldrich) and CNT (Arkema) as piezoelectric (30\% vol.) and conductive fillers (1\% vol.) respectively. Polyamide (PA) from Arkema was used as the polymer matrix. At this scale $\mathrm{NaNbO}_{3}$ cannot be used, since it is not available yet in large-scale production. Fillers were dispersed using a twin-screw extruder from XTRUTECH XTS 24-42 L/P. Figure 2 shows a scanning electron microscopy three phase nanocomposite and a carbonfiber aluminum-honeycomb sandwich panel with the embedded damping film as a patch in the surface of every side of the panel. Additionally, different payloads were fixed to the structure in order to explore wider energy and different frequency ranges.

In order to evidence the transduction-dissipation phenomenon, a polarization step of the nanocomposites films is mandatory. Polarization leads to the orientation of piezoelectric particle $\mathrm{NaNbO}_{3}$ and $\mathrm{BaTiO}_{3}$ electrical dipoles and promotes piezoelectricity. The Curie temperature of $\mathrm{BaTiO}_{3}$ $\left(130{ }^{\circ} \mathrm{C}\right)$ and $\mathrm{NaNbO}_{3}\left(290{ }^{\circ} \mathrm{C}\right)$ are lower than the melting temperature of $\mathrm{PA}\left(180^{\circ} \mathrm{C}\right)$ and $\operatorname{PEKK}\left(331^{\circ} \mathrm{C}\right)$. According to this, the films had to be embedded before the polarization process in order to avoid depolarization. Both structures, the sandwich beams and panels containing the nanocomposite, were poled under an electric field above the glass transition temperature of the polymer matrix but below the Curie temperature of particles for $1 \mathrm{~min}$. More details about the poling process used for filled polymers are described by Capsal et al [31, 33]. Composite panels were polled by corona effect. To our knowledge this process was already used to pole piezoelectric polymers $[34,35]$, two phase and three phase composites [36, 37]. However, to our knowledge, it was never used in a film embedded in a composite structure.

\subsection{DMA for laboratory scaled samples}

2.2.1. Isothermal analysis. DMA analysis was performed by an ARES strain control rheometer in the rectangular shear mode where the stress restored by the sample is measured. The strain-stress hysteresis loop representation was studied. When shear stress $\sigma(\omega)$ is plotted as a function of shear strain $\gamma(\omega)$ for one period of strain (after stabilization of the signal), $\sigma(\omega)$ describes a loop where its area directly represents the dissipated energy per cycle [38].

Hysteresis loops of PEKK at $25^{\circ} \mathrm{C}$ are presented in figure 3 for an amplitude range of shear strain between $0.1 \%$ (linear domain) and 1\%. According to Piollet et al [39], the stressstrain loops observed are composed of a linear part and a hysteresis part carrying the dissipative and nonlinear behavior of 

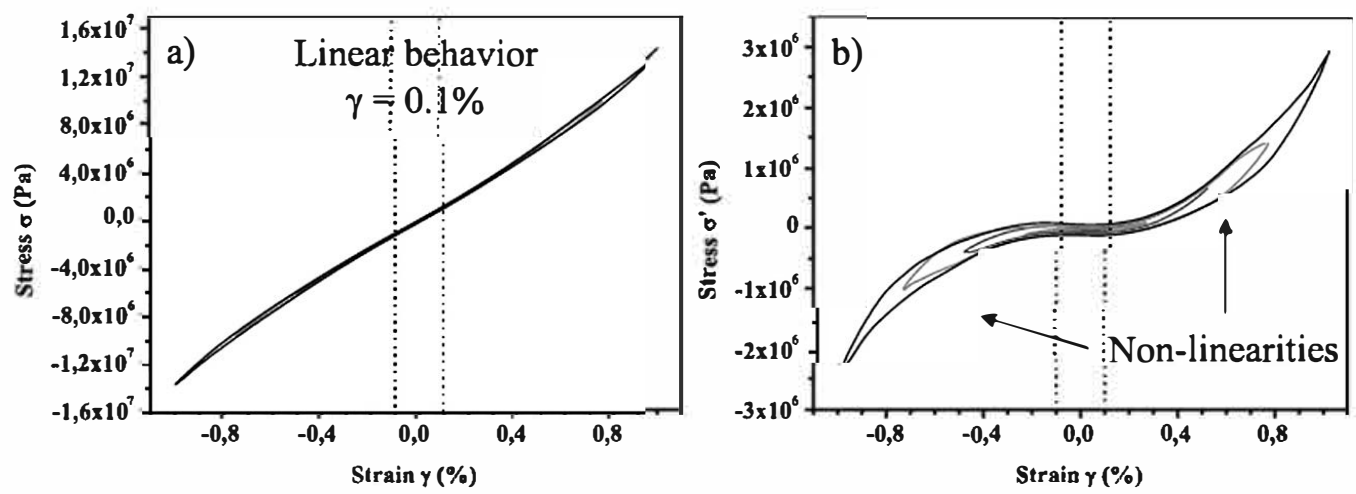

Figure 3. Hysteresis loops of PEKK at $25^{\circ} \mathrm{C}$ before (a) and after (b) the subtraction of the linear part for different imposed strain amplitudes.

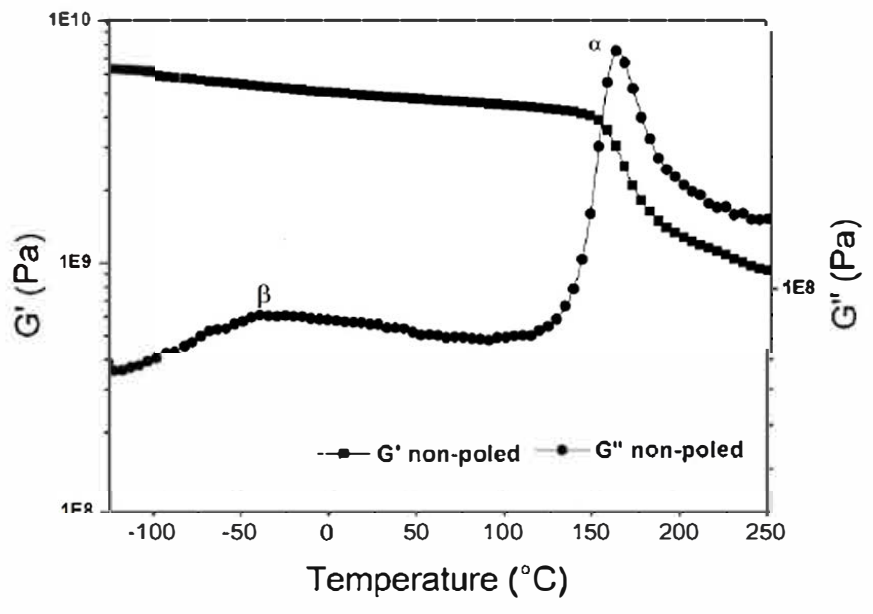

Figure 4. Storage $\left(\mathrm{G}^{\prime}\right)$ and loss $\left(\mathrm{G}^{\prime \prime}\right)$ modulus versus temperature at $1 \mathrm{rad} \mathrm{s}^{-1}$ for PEKK.

the material. To highlight the dissipated energy of the nanocomposite, one subtracts the linear part to the stress $\sigma$ as follows:

$$
\sigma^{\prime}=\sigma-P \gamma
$$

where $P$ is the slope measured at $\gamma(\omega)=0.1 \%$.

The $\sigma^{\prime}(\omega)$ plotted versus $\gamma(\omega)$ is showed in figure 3(b)). The complex shape (non-ellipsoid) for strains higher than $0.1 \%$ is characteristic of non-linear behavior of the material. Stress follows cubic law as a function of the strain.

2.2.2. Dynamic temperature analysis. Shear dynamic mechanical storage modulus and loss modulus, $G^{\prime}$ and $G^{\prime \prime}$, were recorded as a function of the temperature (figure 4). Measurements were achieved in a temperature range of $-130{ }^{\circ} \mathrm{C}$ to $250{ }^{\circ} \mathrm{C}$, with a scanning rate of $3{ }^{\circ} \mathrm{C} \mathrm{min}-1$. The angular frequency $(\omega)$ was $1 \mathrm{rad} \mathrm{s}^{-1}$ and the strain $(\gamma)$ was $10^{-1} \%$.

\subsection{Vibration tests}

Vibration tests were performed using an electrodynamic shaker LDS V830-335 SPA16K 10KN from BRÜEL \&
KJAER. Vibration tests consist in applying a translational dynamic solicitation with controlled loop and measuring the material dynamic response as a function of excitation frequency through an acceleration transmissibility function (ATF). For laboratory scaled sandwich beams, acceleration measurements were made with a PSV-500 Xtra laser vibrometer from POLYTEC, without contact to avoid additional mass that may possibly influence the bending resonance mode. The beams were disposed in the vertical direction and clamped in the vibrating table support at one of its extremities (cantilever beam-see figure 5). Sandwich panel's response was measured by placing 15 accelerometers in the lower surface of the panel. The excitation was done in the vertical direction. The structure was fixed to the shaker by means of two flexible aluminum brackets. In both cases it was ensured that the positioning and the clamping did not influence the dynamic response of the samples tested.

\section{Results and discussion}

\subsection{Laboratory scaled samples: sandwich composite beams}

3.1.1. Energy dissipation mechanisms with non-poled particles. The aim of this paper is to enhance the dissipated mechanical energy capability of composite structures used for aeronautical and spatial applications. For this purpose, a damping film is placed between two plies of carbon. The procedure adopted for designing this film was first to investigate the dissipation energy capability of the materials, i.e.: the unfilled PEKK matrix and non-poled PEKK filled with $\mathrm{NaNBO}_{3}$ and $\mathrm{CB}$; and later the sandwich carbon composite beam (symmetric) with the damping film embedded. Hysteresis loop areas determined at $0.1 \%$ strain and $25^{\circ} \mathrm{C}$ are reported in figure 6 for each configuration.

The introduction of ceramic and carbon particles leads to a three-fold increase in the dissipated energy compared with unfilled PEKK. This result might be related, among other possible effects, with the localized stick-slip phenomenon at the interface between rigid particles and soft matrix. Indeed, researchers believe that the addition of nanoparticles results in a large interfacial contact area and high friction energy dissipation during the sliding of nanoparticle surfaces 


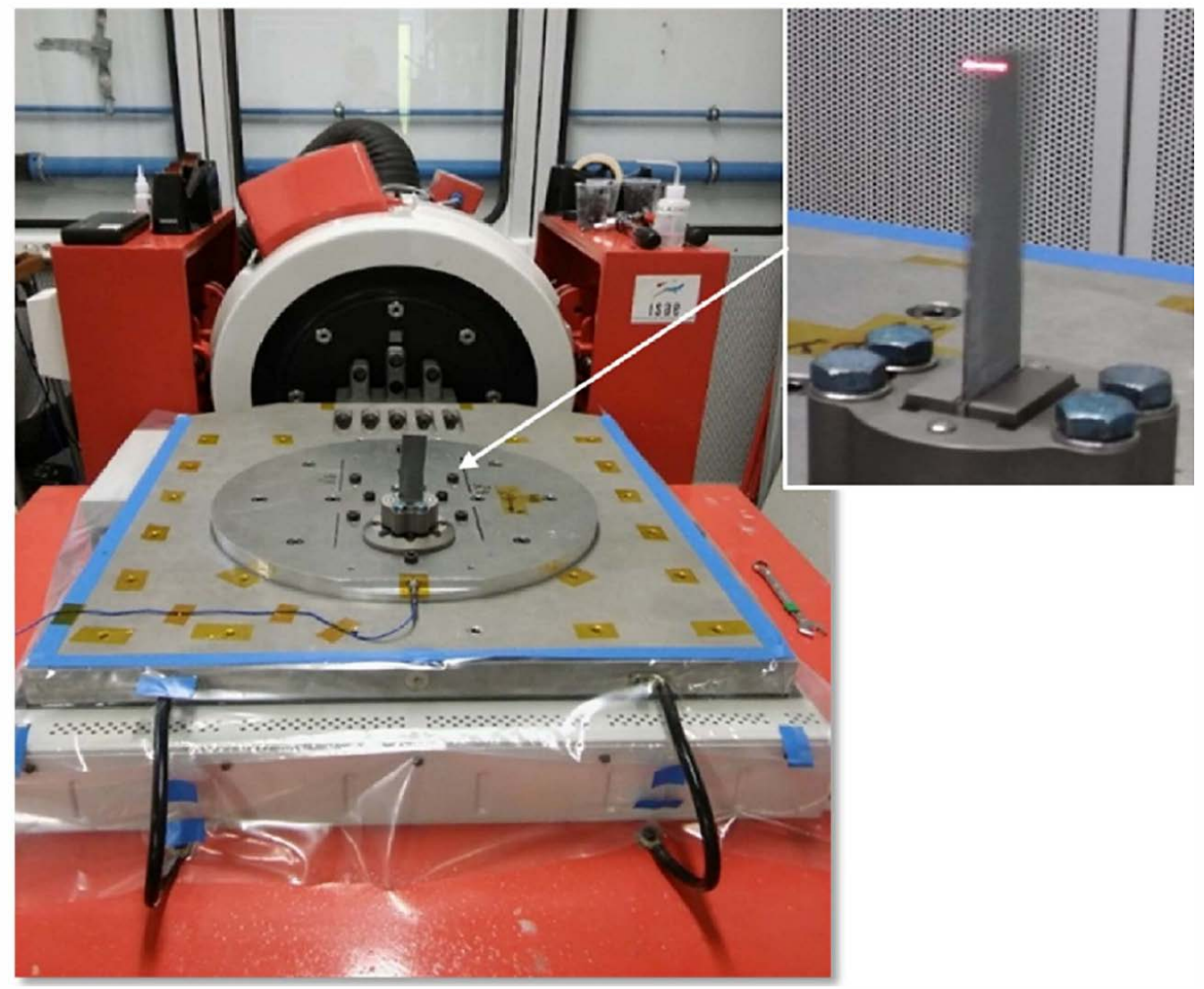

Figure 5. Illustration of the test bench for vibration analysis of beam.

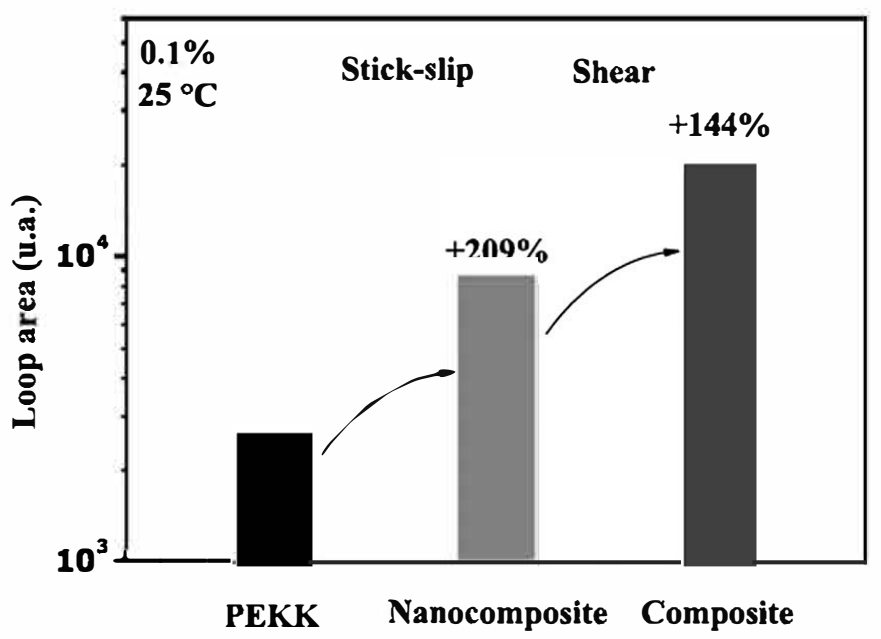

Figure 6. Hysteresis loops area determined at $0.1 \%$ strain and $25^{\circ} \mathrm{C}$ for each configuration (non-poled samples).

within the polymer matrix [40]. Dissipated energy is further increased (by 144\%) when the nanocomposite film is integrated between composite plies in the sandwich configuration (figure l(b)). This contribution is mainly due to shear stress at the UD tape and nanocomposite film interlayers [11]. Stickslip phenomenon between carbon fibers and the UD tape matrix may also increase the dissipated energy.
Further to improvements on the characterization of the damping film, the DMA was performed to access the influence of the temperature environment and strain level. Hysteresis loops were then obtained for the sandwich beam at $162^{\circ} \mathrm{C}$ ( $T$ gPEKK$_{\text {PE }}$ and $25^{\circ} \mathrm{C}$ at different strain levels. Figures 7 (a) and (b) show the experimental results obtained and the loop area was determined and reported in figure 8 .

A non-ellipsoid shape of the loops is observed in figure 7 , as in the case of the unfilled PEKK, highlighting non-linear behavior for strain higher than $0.1 \%$. Hysteresis loop areas are greatly augmented by increasing the temperature and the strain level. The dissipated energy has increased by $7.8-$ 2.7 times at 0.1 and $1 \%$ strain respectively when comparing the hysteresis loop areas between $25^{\circ} \mathrm{C}$ and $162{ }^{\circ} \mathrm{C}$ (glass transition temperature $T_{\mathrm{g}}$ ). Moreover, regarding the increment of the strain level from $0.1 \%$ to $1 \%$, the dissipated energy increased by 500 times and 200 times at $25^{\circ} \mathrm{C}$ and $162^{\circ} \mathrm{C}$, respectively. The dissipation mechanism, in this case, is related to the temperature and strain level. This fact might be explained firstly by the nonlinear viscoelasticity of the PEKK: the material loss factor increases in the vicinity of the glass transition temperature and the high strain amplitude leads to nonlinear effects which engenders energy dissipation [41]. Regarding the possible dissipation mechanism provided by the stick-slip phenomenon, the increased stress induced by the high strain amplitude is favorable for the dissipation mechanism. Nonetheless, the increment in temperature degenerates 

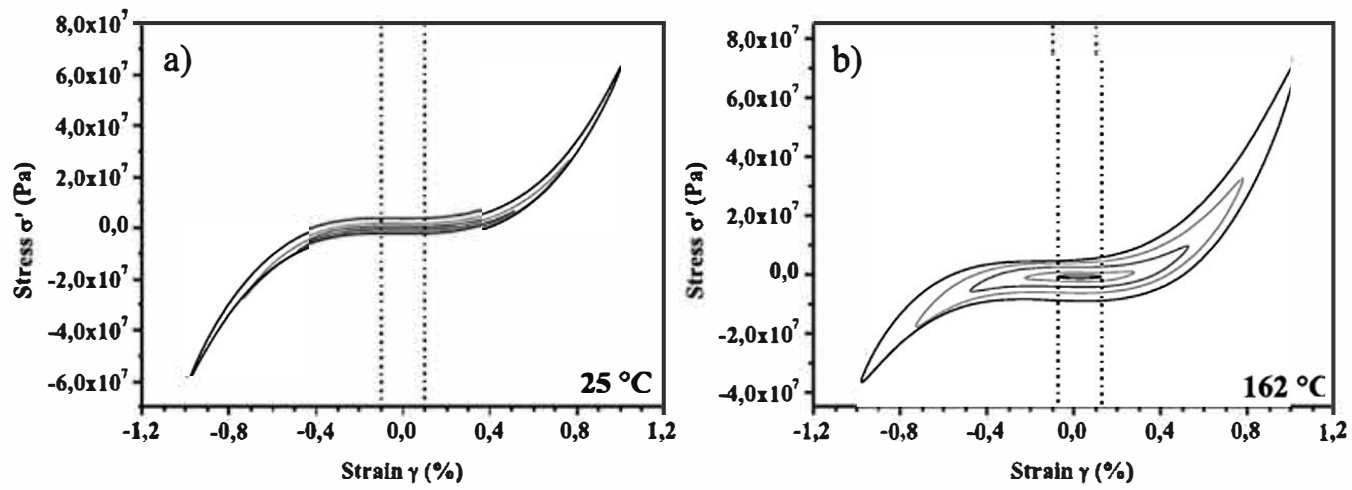

Figure 7. Hysteresis loops of laboratory scaled sandwich bearns at $25^{\circ} \mathrm{C}$ (a) and $162^{\circ} \mathrm{C}$ (b) after the subtraction of the linear part.

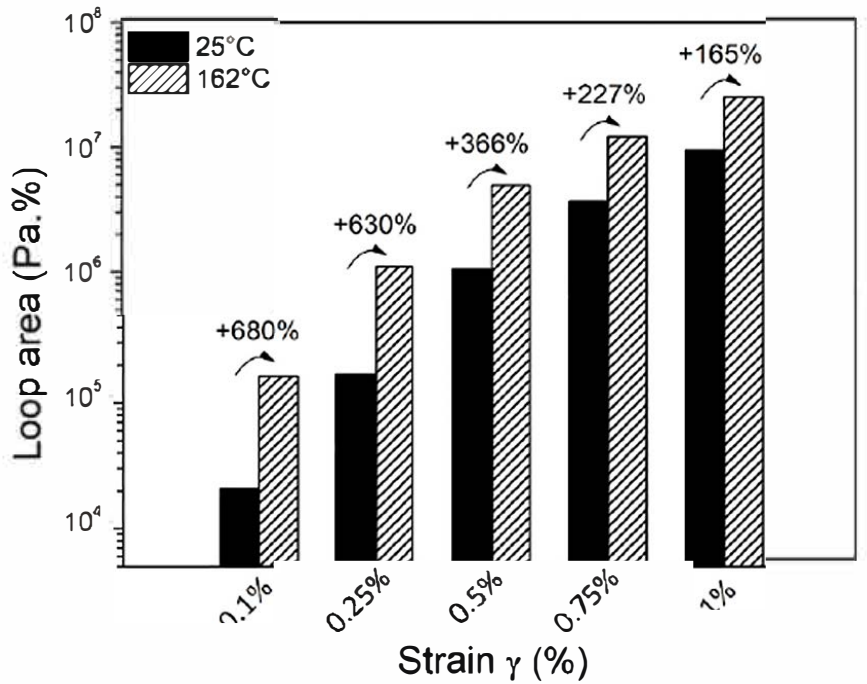

Figure 8. Hysteresis loop area versus strain for laboratory scaled sandwich beams in the symmetric configuration at $25^{\circ} \mathrm{C}$ and $162^{\circ} \mathrm{C}$.

the mechanical properties of the polymer which reduces the damping performance of the composite structure. Viscoelasticity, friction and piezoelectric damping have also been reported by Zhang et al [29] for chlorinated polyethylene/barium titanate/vapor-grown carbon fiber composites, and Carponcin et al [26] for PA 11/PZT/CNT composites.

3.1.2. Polarization infuence. The previous section highlighted the enhancement of dissipated mechanical energy attained by the damping film embedded in the composite sandwich beam. The nanocomposite film filled with non-poled particles mainly owes its damping capabilities to the matrix's viscoelasticity and stick-slip phenomenon. The aim of this section is to evidence the contribution of the transductiondissipation phenomenon after the polarization process: when nanocomposite films become piezoelectric at a macroscopic scale. This contribution was followed through the analysis of the hysteresis loops area. Figure 9 represents the hysteresis loops of the composite sandwich beam in symmetric configuration with non-poled and poled particles. The loops

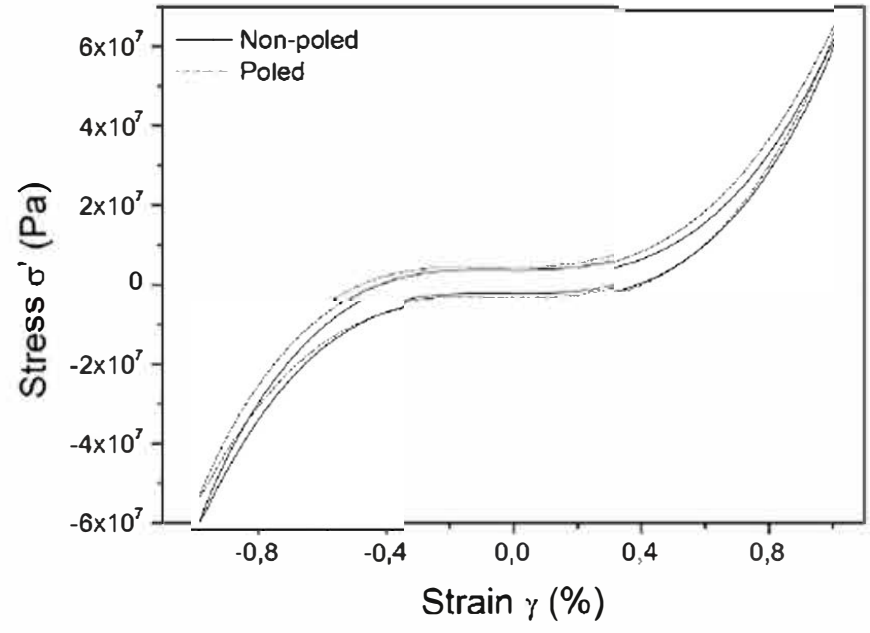

Figure 9. Hysteresis loops of composites in symmetric configuration, at $25^{\circ} \mathrm{C}$, before polarization (solid lines) and after polarization (dotted lines).

were determined at different strain levels, $1 \mathrm{rad} \mathrm{s}^{-1}$ and $25^{\circ} \mathrm{C}$ and respective area values were reported in figure 10 .

Indeed, the study of damping behavior through hysteresis loops was already used for filled materials and complex systems like composite structures, sandwich structures or assemblies at larger scales [39, 42-44]. In addition to viscous damping, stick-slip and shear dissipations, local transductiondissipation phenomenon is highlighted by a further increase in dissipated energy from $16 \%$ at $0.1 \%$ of shear strain amplitude to $34 \%$ at $1 \%$ strain level. The experimental results highlighted an increase in energy dissipation after the polarization process of composite sandwich beams, bringing proof of concept of the transduction-dissipation phenomenon.

Beyond the DMA tests on the composite sandwich beam done at different strain levels and constant temperature, it was interesting to observe the evolution of the storage and loss modulus in a large temperature range for the non-poled and poled damping film (figure 11) at low strain amplitude and frequency.

Bulk samples of the damping films were only tested in order to avoid to mask sensitive polymer relaxations by the CFRP. Regarding the storage modulus $G^{\prime}$, no real influence of 


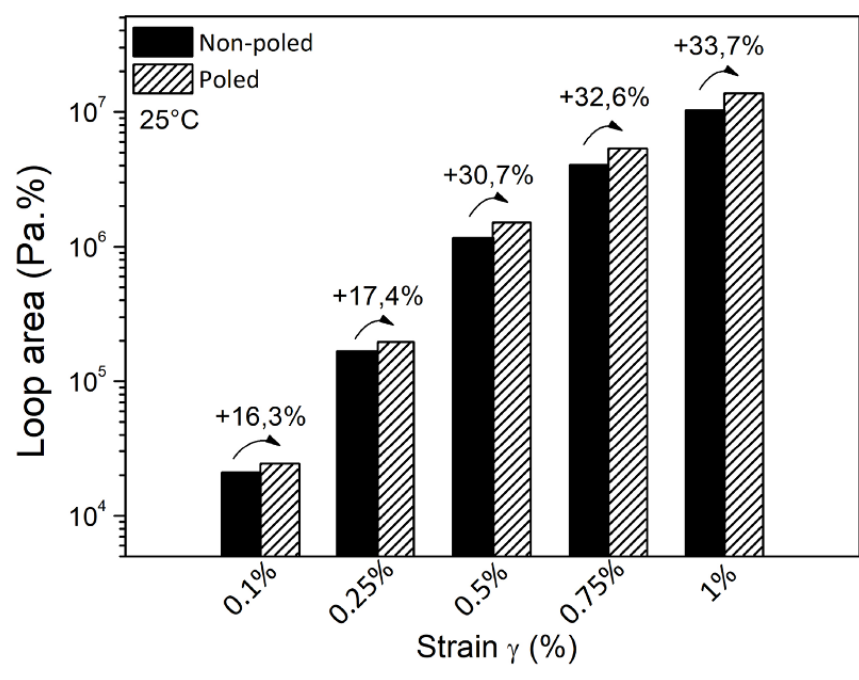

Figure 10. Hysteresis loop area of composite beam determined at $25^{\circ} \mathrm{C}$ as a function of strain, before and after polarization.

polarization was observed. Dissipative modulus $G^{\prime \prime}$ of PEKK evidenced two relaxations, noted $\beta$ and $\alpha$ at $-36{ }^{\circ} \mathrm{C}$ and at $160{ }^{\circ} \mathrm{C}$ respectively. The polarization process strengthened the localized relaxation $\beta^{*}$ with respect to $\beta$ relaxation in the low temperature region. However, at higher temperatures, no conclusion could be made as to the influence of polarization in the $\alpha$ mode.

In order to better compare these relaxations and the influence of polarization, dissipative modulus for poled and nonpoled samples were normalized under a common baseline, previously determined by analytical fitting (figure 11(b)).

In figure 11(b), the poled sample exhibits increased amplitude of $\alpha$ mode: the area under the curve was found to be increased by $18 \%$ compared to the non-poled sample, highlighting the transduction-dissipation phenomenon. These results are in agreement with Carponcin et al [26] where an amplitude increase in $\alpha$ relaxation of $10 \%$ was observed in PA damping nanocomposites and related to transduction dissipation phenomenon.

$\beta^{*}$ relaxation is directly linked with a successful polarization process of ceramic particles dispersed in PEKK. Beyond this fact, however, the link between this relaxation and the transduction-dissipation phenomenon is not clear and needs some further investigation. It is known from the literature that the molecular origin of $\beta$ relaxation of PEKK is related to polar and phenylene unit mobility around the polymer chain [45]. Therefore, $\beta^{*}$ relaxation could be related to the enhancement of dipolar interactions of the polymer chain after the polarization process and/or related with the localized dipolar interactions of the polymer chain with charges generated by piezoelectric particles.

In order to highlight the enhancement of the beta relaxation in the vibration tests, time-temperature equivalence principle of the viscoelastic material was performed in order to estimate the optimal excitation frequency of the poled sample.

Based on the Arrhenius model $\left(\tau(T)=\tau_{0} \mathrm{e} \frac{\Delta H}{R T}\right.$ ), (where $\tau(T)$ is the relaxation time, $\Delta H$ is the apparent activation energy, $R$ is the gas constant and $\tau_{0}$ is the preexponential factor) it is possible to determine the relaxation frequency of $\beta$ and $\beta^{*}$ modes at $25{ }^{\circ} \mathrm{C}$ (corresponding to vibration test temperature) since the relaxation temperature is equivalent. Thanks to dielectric dynamic spectroscopy results, the $\tau_{0}$ factor and the activation enthalpy $\Delta H$ determined experimentally are $4.28 \times 10^{-15} \mathrm{~s}$ and $65.06 \mathrm{~kJ} \mathrm{~mol}^{-1}$, respectively [46]. The $\tau_{\beta}$ at $25^{\circ} \mathrm{C}$, was calculated $1.07 \times 10^{-3} \mathrm{~s}$, which corresponds to a frequency of $933 \mathrm{~Hz}$.

\subsubsection{Influence of polarization on the dynamic response:} vibration tests. To highlight the local transductiondissipation phenomenon of the nanocomposite film at higher frequencies (compared to DMA), the dynamical behavior of the sandwich composite beam is investigated during the two first resonance conditions (i.e.: $180 \mathrm{~Hz}$ and $1100 \mathrm{~Hz}$ ). Indeed, the properties of viscoelastic materials might be affected by the oscillation frequency and the characterization of the hysteresis loops of the nanocomposite film during DMA tests at low frequency. Moreover, the samples were designed to have a resonance frequency around $1 \mathrm{kHz}$ for investigation into the enhancement of $\beta^{*}$ relaxation mode after polarization (as discussed in the previous section). Figure 12 represents the ATFs, before and after polarization of the first and second bending modes of a composite beam at different acceleration levels (between $0.25 \mathrm{~g}$ and $4 \mathrm{~g}$ ).

The first bending mode occurs at around $180 \mathrm{~Hz}$ for this sample beam configuration, accordingly to figure 12(a). For both non-poled and poled cases, the results show an amplitude decrease when imposed acceleration increases, highlighting nonlinear damping behavior on the dynamic response of the samples. This phenomenon has already been also observed by considering friction damping, among other examples of nonlinear damping sources, in structures [33, 47]. These results agreed with those obtained by DMA tests. Indeed, increasing vibration amplitude (from $0.25 \mathrm{~g}$ to $4 \mathrm{~g}$ ) increases the strain level in the material. Based on figure 10, dissipated energy (loop area) increases with the strain level which explains the decrease in the vibration amplitude. This significant decrease could be attributed to intrinsic dissipation mechanisms (localized stick-slip at matrix-particle interfaces, shear, viscoelasticity) of the materials previously highlighted for this kind of sample.

Comparing the resonant peak amplitude between nonpoled and poled configurations, a decrease in amplitudes was achieved after polarization for a certain excitation level: amplitude decreased $25 \%$ to $4 \%$ for an acceleration from $0.25 \mathrm{~g}$ to $4 \mathrm{~g}$ respectively. Data is available in figure 13 . Clearly, the polarization process leads to damping increase in the structure.

Concerning the 2 nd bending resonant mode, it is located at a higher frequency near $1100 \mathrm{~Hz}$ (figure 12(b)). As it was shown for the 1st resonant mode, the amplitude at resonant peak decreases when the imposed acceleration increases, regardless of the polarization, evidencing nonlinear behavior of the structure. However, for the second bending mode the decrease in the resonance amplitude is less significant compared to the first mode: intrinsic dissipation mechanisms 

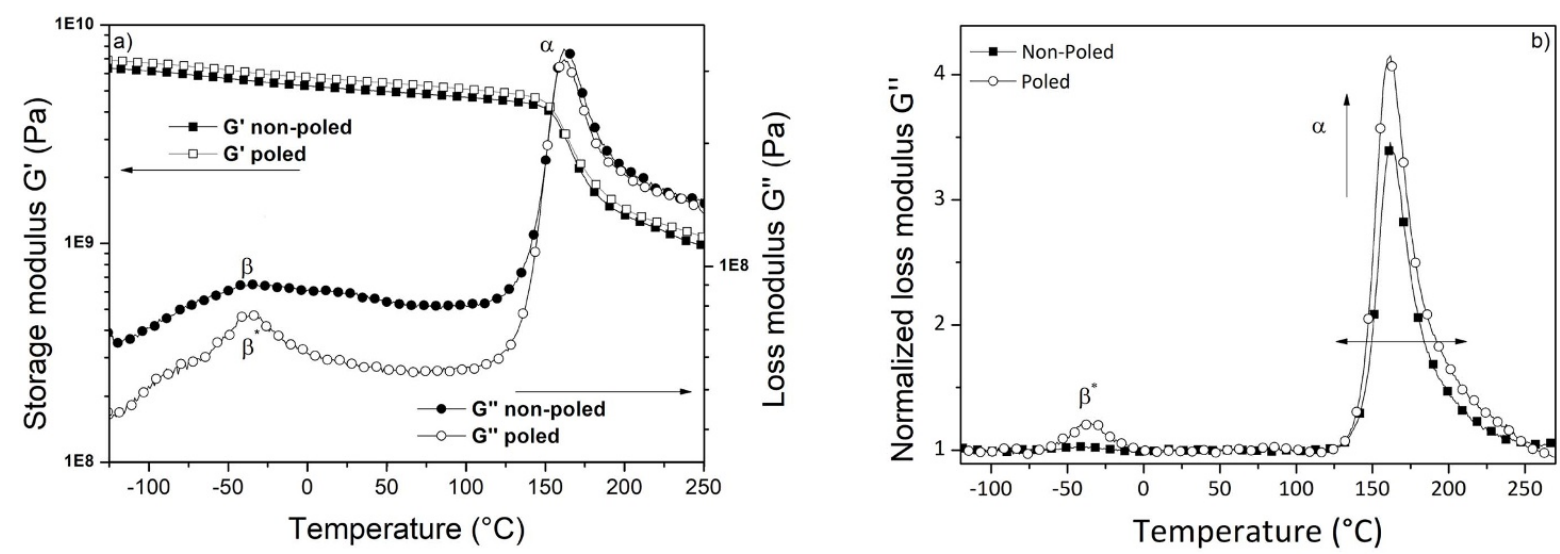

Figure 11. Storage and loss modulus evolution with temperature for non-polled and polled samples: (a) without normalization and (b) with normalization.
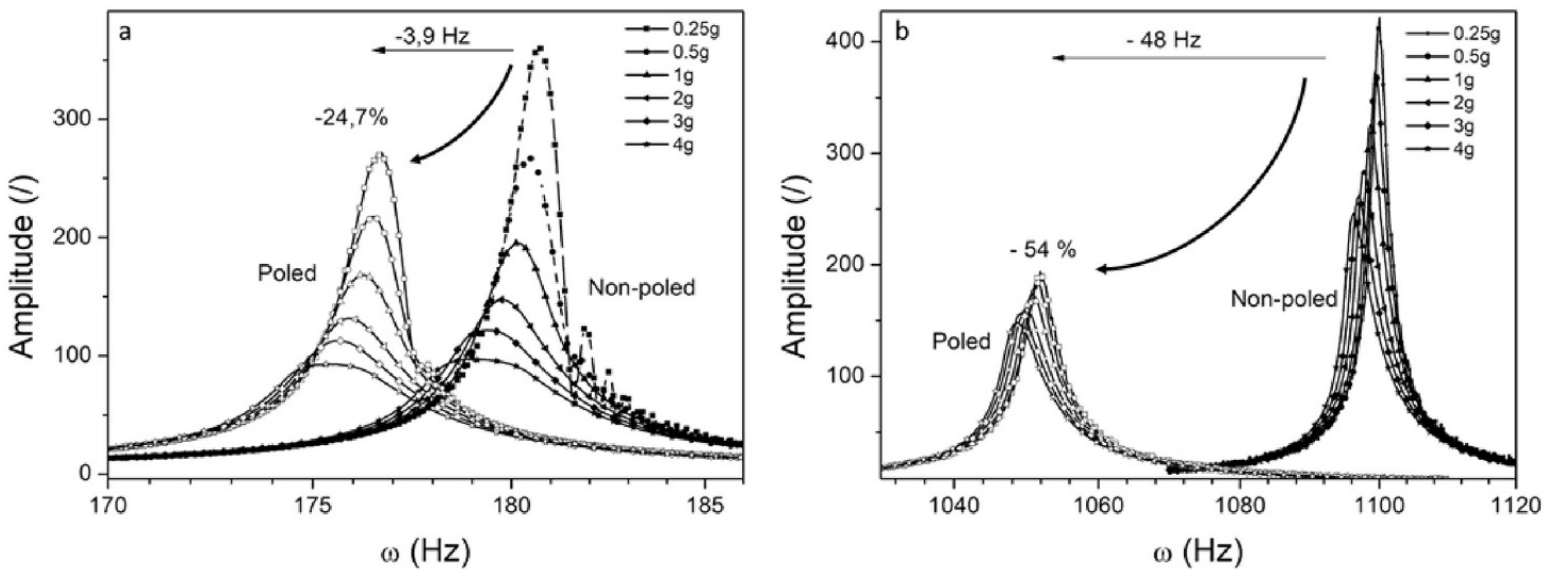

Figure 12. ATF of a composite beam before and after polarization at: (a) 1st bending mode and (b) 2nd bending mode.

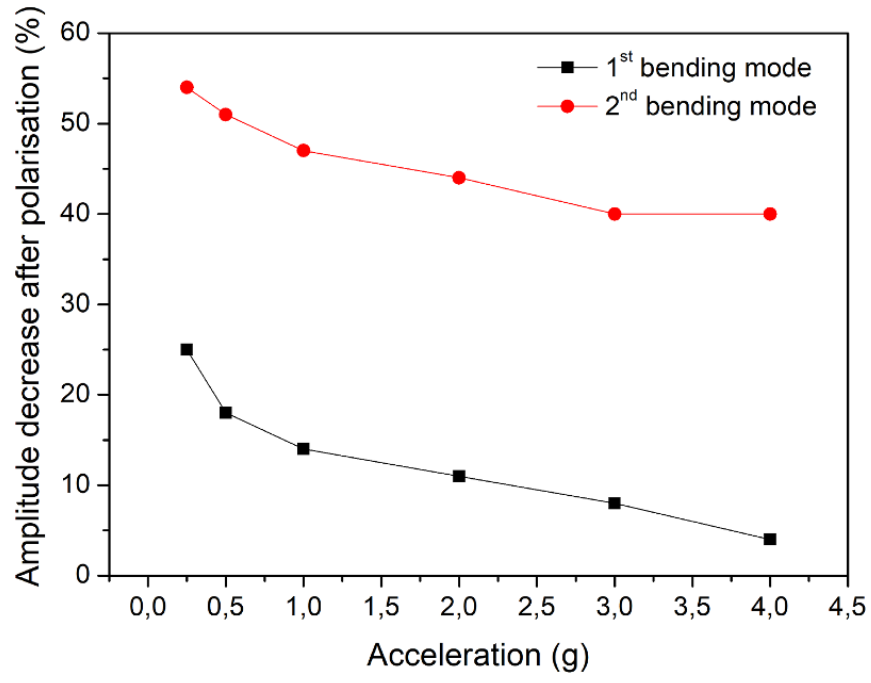

Figure 13. Amplitude decrease versus imposed acceleration for the 1 st and 2 nd bending modes.

seem to be less efficient at this frequency for the 2 nd resonant mode.

Here the comparison of the resonant amplitudes for nonpoled and poled samples at several excitation levels show a larger decrease in amplitude after polarization, from $54 \%$ decrease at $0.25 \mathrm{~g}$ and $40 \%$ at $4 \mathrm{~g}$ (see figure 13). These results reveal the great performance of the damping film at higher frequency for sandwich composite beams with poled particles.

For laboratory scale structures, the damping performance achieved in all the frequency ranges is related to the local transduction-dissipation phenomenon. Based on experiments this phenomenon seems to be more significant at higher $(1100 \mathrm{~Hz})$ than at low $(180 \mathrm{~Hz})$ frequencies. The corresponding frequency of the second bending mode matches $\beta^{*}$ relaxation (figure 11) frequency at room temperature $\left(25^{\circ} \mathrm{C}\right)$ determined by the time-temperature equivalence, as previously described. The fact that this transduction-dissipation phenomenon is more highly performant for the second bending mode could be associated with this equivalence.

Regarding the resonance frequencies variation observed after the polarization process, a shift of $4 \mathrm{~Hz}$ and $48 \mathrm{~Hz}$ are verified for the 1 st and 2 nd bending modes, respectively. These variations correspond to $2 \%$ and $4 \%$ of the 1 st and 2 nd resonance frequencies, respectively. Previous investigations proved that the shift is not related to the sample positioning in the shaker or the temperature applied during the poling step. This phenomenon was already reported by Carponcin et al [26], 

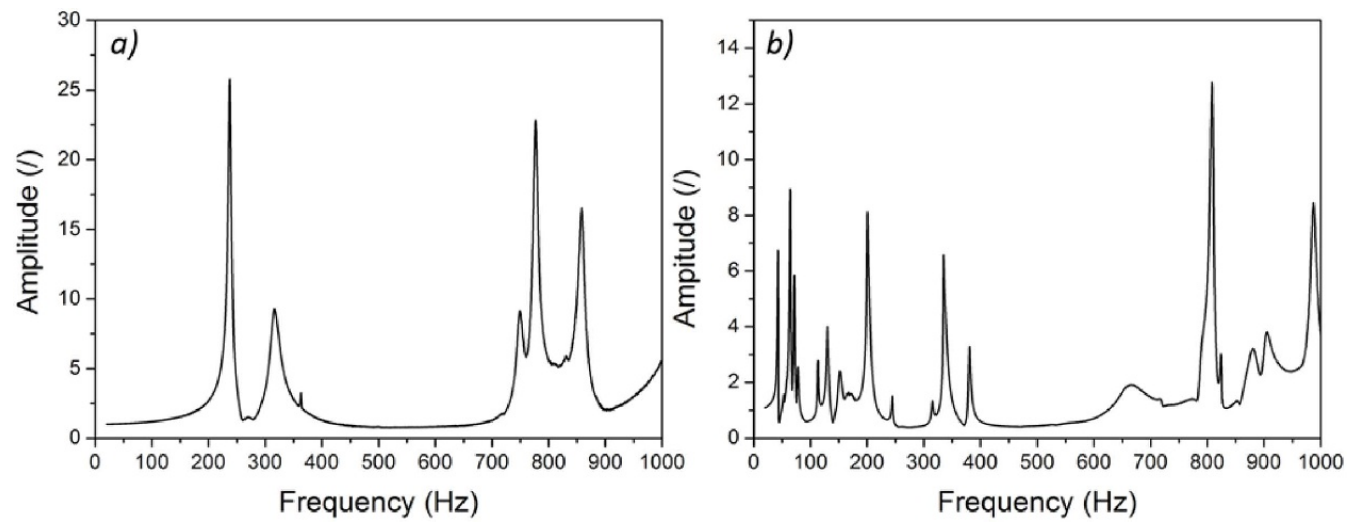

Figure 14. ATF of a sandwich panel with two different payload configurations: (a) no payloads; (b) $22 \mathrm{~kg}$ payload.

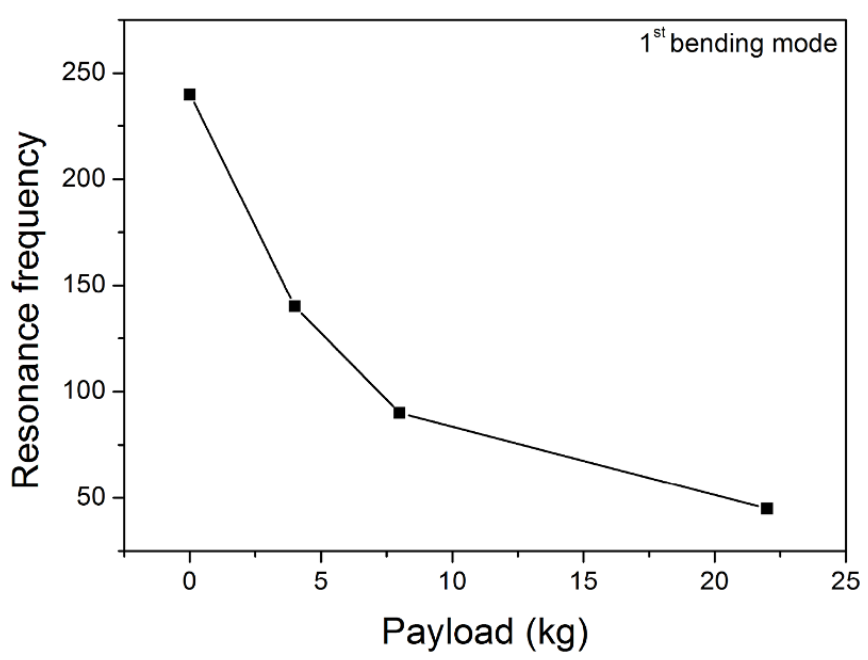

Figure 15. Evolution of the 1st bending mode's resonance vs payload.

however it is not clear yet how polarization could lead to this shift.

\subsection{Carbon-fiber aluminum-honeycomb sandwich panel}

Different payload configurations were used to study the sandwich panel in order to explore a wider energy and frequency range: adapting the payloads and thus the configuration of the panel allow us to pilot the resonances towards more useful frequencies depending on the application. However, adding payloads increases the modal density and brings complexity to the ATF as observed in figure 14 .

In order to focus the investigation into damping film influence at different energy and frequency ranges, only the 1st bending mode is studied and used as a reference. Indeed, the 1 st bending mode shape is almost the same for the panel at all payload configurations, while the resonance frequency varies (figure 15). The highest resonance frequency is related to no payload configuration while the lowest frequency happens with the maximum payload. Tests were performed at low amplitude level $0.25 \mathrm{~g}$ in order to ensure the structural integrity of the panels.

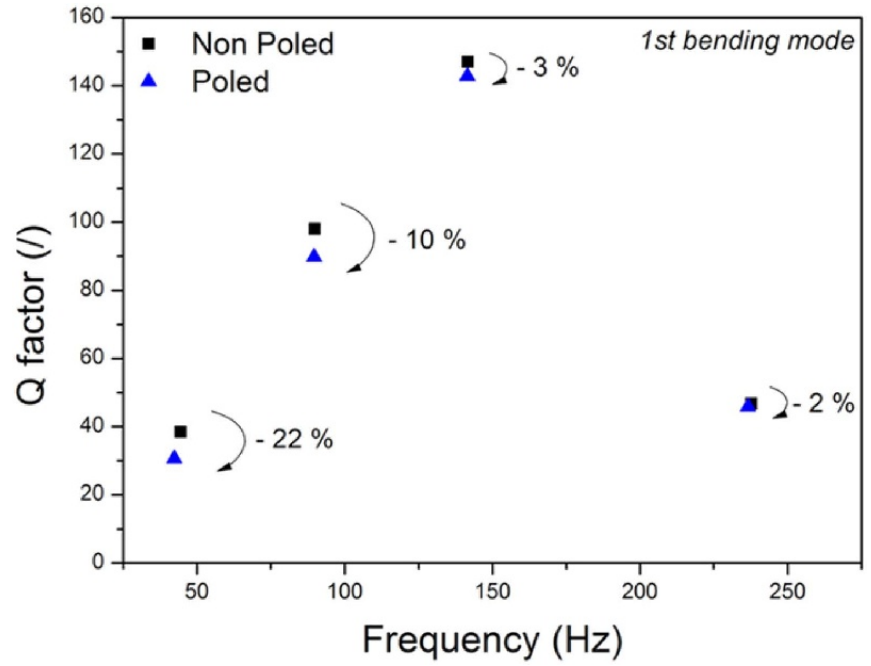

Figure 16. Evolution of the quality factor before and after polarization for different payload configurations.

The experimental results obtained through vibration tests at resonant condition (1st bending mode) are reported in figure 16 for the panel with several payload configurations (frequency). The quality factor (Q-factor), computed from the average measured ATF, is reported as a function of the frequency before and after polarization. It is important to note that the $\mathrm{Q}$ factor amplitude is inversely related to the structural damping level: higher $Q$ factor amplitude means lower structural damping and vice-versa.

Analyzing the results from $250 \mathrm{~Hz}$ down to $50 \mathrm{~Hz}$ (increase in payload) for the panel with non-poled particles, an increase in Q factor (from $250 \mathrm{~Hz}$ to $150 \mathrm{~Hz}$ ) is firstly observed and then a decrease in the amplitude (from $150 \mathrm{~Hz}$ to $50 \mathrm{~Hz}$ ).

In the $50 \mathrm{~Hz}$ to $150 \mathrm{~Hz}$ frequency range, enhancement of structural damping level (decrease in $\mathrm{Q}$ factor) as the payload increases is clearly evidenced. The $\mathrm{Q}$ factor is estimated at around 150 at $150 \mathrm{~Hz}$ (minimum payload configuration) while it attains the level of 40 at $50 \mathrm{~Hz}$ (maximum payload configuration). This enhancement of structural damping could be related, among others, to the dissipation mechanism of the damping film in the structure. Indeed, as observed from 
the DMA tests, the increment of the strain level (payload) in the damping film leads to high dissipated energy capability (figure 10).

Beyond this fact, an important point to be highlighted is the enhancement of the panel structural damping after the polarization process. A decrease of about $3 \%$ in the $\mathrm{Q}$ factor amplitude at $150 \mathrm{~Hz}$ is attained while a reduction of $22 \%$ is observed at $50 \mathrm{~Hz}$. Clearly, an increment in the performance capability of the damping film to dissipate energy after the polarization process (a damping enhancement of 3\% up to $22 \%$ with higher strain/energy levels) is observed. This result agrees with those obtained with DMA tests for poled samples where the increment in dissipated energy was higher for higher strain levels (figure 10).

Generally, this investigation reveals that the proposed damping film has a great capacity for dissipating vibratory energy from laboratory scale (bulk material sample and small beam structure) up to industrial applications (panel) thanks to the transduction-dissipation phenomenon. Indeed, the mechanical vibration generates electric charges in the piezoelectric particles which, combined with the electric resistive fillers, engender new dissipation mechanisms (beyond those mechanisms from the polymer matrix). The performance of the damping film in composite structures has been evaluated extensively through several experimental tests in different operational conditions. The analyses reveal the damping performance as a function of the operational frequency and the energy level. A higher frequency stimulates the damping enhancement observed in the beta relaxation mode, while higher energy allows the generation of a higher amount of electric charges in the piezoelectric particles.

Concerning the $\mathrm{Q}$ factor level for the panel without payload $(250 \mathrm{~Hz})$, it has almost the same amplitude for the case at $50 \mathrm{~Hz}$ (maximum payload) indicating high structural damping level. Moreover, the polarization process does not alter the $\mathrm{Q}$ factor level: a reduction of $2 \%$ in $\mathrm{Q}$ factor amplitude was observed. Beyond the fact of low strain level (panel without payload) and frequency other than $1 \mathrm{kHz}$, these conditions are not ideal to highlight the benefits of the damping film.

\section{Conclusion}

Here a passive vibration damping concept for composite structures was studied at laboratory and preindustrial scale. Damping nanocomposite films were elaborated by dispersing piezoelectric and conductive particles in PA or PEKK polymers which were subsequently embedded into laboratory scaled composite beams and preindustrial scaled CFRP-aluminum honeycomb panels. Furthermore, the material capacity to dissipate energy was shown via a multi-scale study: from material-scale up to preindustrial-scale specimen arrangements.

DMA allowed us to identify classical mechanisms of energy dissipation of the structure at laboratory scale: viscoelasticity (viscous damping), stick-slip (interfacial frictional movement) and shear stresses between carbon fibers and the constrained film. Additionally, a supplementary dissipation mechanism was highlighted by an increase in dissipated energy of up to $34 \%$ after the polarization step: local transduction-dissipation was related to the synergy of piezoelectric and conductive particles.

This contribution was also highlighted through vibration tests: at laboratory scale, the study of the 1 st and 2 nd bending mode at resonance evidenced remarkable damping performance specifically at high frequency, where an amplitude decrease of up to $54 \%$ was achieved. However, results for CFRP-aluminum panels indicated that the transductiondissipation phenomenon is not only frequency-dependent but also energy-dependent: results revealed the increase in structural damping from $3 \%$ to $22 \%$ with the imposed energy/strain on the structure. These results were in agreement with DMA analysis proving the necessity of multi-scale studies to reveal the real efficiency of damping for composite structures by nanocomposite films containing piezoelectric and conductive particles.

\section{Data availability statement}

The data that support the findings of this study are available upon reasonable request from the authors.

\section{Acknowledgments}

These results were obtained under the research project 'COMPINNOVTP' at the IRT Saint Exupéry. We thank the industrial and academic members of the IRT who supported this project through their contributions, both financial and in terms of specific knowledge: AIRBUS OPERATIONS, ARIANE GROUP, AIRBUS HELICOPTERS, AIRBUS GROUP INNOVATIONS, THALES ALENIA SPACE, CIRIMAT, ISAE, ICA, IMRCP, UPS and CNRS. Special thanks to the Ariane Group for supplying the composites panels for this study. We also thank the Commissariat Général aux Investissements and the Agence Nationale de la Recherche for their financial support in the Programme d'Investissement d'Avenir (PIA).

\section{ORCID iDs}

C Lacabanne (D) https://orcid.org/0000-0003-3286-9707

G Michon (D) https://orcid.org/0000-0003-0747-7680

\section{References}

[1] Tanimoto T 2002 Carbon-fiber reinforced plastic passive composite damper by use of piezoelectric polymer/ceramic Japan. J. Appl. Phys. 41 7166-9

[2] Kapuria S and Yasin M Y 2010 Active vibration control of piezoelectric laminated beams with electroded actuators and sensors using an efficient finite element involving an electric node Smart Mater. Struct. 19045019

[3] Sharma A, Kumar A, Susheel C K and Kumar R 2016 Smart damping of functionally graded nanotube reinforced composite rectangular plates Compos. Struct. 155 29-44 
[4] Gripp J A B and Rade D A 2018 Vibration and noise control using shunted piezoelectric transducers: a review Mech. Syst. Signal Process. 112 359-83

[5] Ghosh D and Gopalakrishnan S 2005 Coupled analysis of composite laminate with embedded magnetostrictive patches Smart Mater. Struct. 141462

[6] Suhr J and Koratkar N A 2008 Energy dissipation in carbon nanotube composites: a review J. Mater. Sci. 43 4370-82

[7] Saviz M 2015 An optimal approach to active damping of nonlinear vibrations in composite plates using piezoelectric patches Smart Mater. Struct. 24115024

[8] Tanimoto T 2002 Interleaving methodology for property tailoring of CFRP laminates Compos. Interfaces 9 25-39

[9] Treviso A, Van Genechten B, Mundo D and Tournour M 2015 Damping in composite materials: properties and models Composites B 78 144-52

[10] Tang X and Yan X 2020 A review on the damping properties of fiber reinforced polymer composites $J$. Ind. Textiles 49 693-721

[11] Liao F-S, Su A-C and Hsu T-C J 1994 Vibration damping of interleaved carbon fiber-epoxy composite beams J. Compos. Mater. 28 1840-54

[12] Yim J H, Cho S Y, Seo Y J and Jang B Z 2003 A study on material damping of $0^{\circ}$ laminated composite sandwich cantilever beams with a viscoelastic layer Compos. Struct. $60367-74$

[13] Cai C, Zheng H and Liu G R 2004 Vibration analysis of a beam with PCLD patch Appl. Acoust. 65 1057-76

[14] Granger D and Ross A 2009 Effects of partial constrained viscoelastic layer damping parameters on the initial transient response of impacted cantilever beams: experimental and numerical results J. Sound Vib. 321 45-64

[15] Troncossi M, Taddia S, Rivola A and Martini A 2020 Experimental characterization of a high-damping viscoelastic material enclosed in carbon fiber reinforced polymer components Appl. Sci. 106193

[16] Rade D A, Deü J-F, Castello D A, De Lima A M G and Rouleau L 2019 Passive vibration control using viscoelastic materials Nonlinear Structural Dynamics and Damping ed J C Jauregui (Cham: Springer International Publishing) pp 119-68

[17] Liu X F, Xiong C X, Sun H J, Dong L J, Li R and Liu Y 2006 Piezoelectric and dielectric properties of PZT/PVC and graphite doped with PZT/PVC composites Mater. Sci. Eng. B 127 261-6

[18] Tanimoto T 2007 A new vibration damping CFRP material with interlayers of dispersed piezoelectric ceramic particles Compos. Sci. Technol. 67 213-21

[19] Tian S, Cui F and Wang X 2008 New type of piezo-damping epoxy-matrix composites with multi-walled carbon nanotubes and lead zirconate titanate Mater. Lett. 62 3859-61

[20] Tian S and Wang X 2008 Fabrication and performances of epoxy/multi-walled carbon nanotubes/piezoelectric ceramic composites as rigid piezo-damping materials J. Mater. Sci. 43 4979-87

[21] Ma M and Wang X 2009 Preparation, microstructure and properties of epoxy-based composites containing carbon nanotubes and PMN-PZT piezoceramics as rigid piezo-damping materials Mater. Chem. Phys. 116 191-7

[22] Kim S Y, Tanimoto T, Uchino K, Nam C H, Nam S and Lee W I 2011 Effects of PZT particle-enhanced ply interfaces on the vibration damping behavior of CFRP composites Composites A 42 1477-82

[23] Banerjee S and Cook-Chennault K A 2012 An investigation into the influence of electrically conductive particle size on electromechanical coupling and effective dielectric strain coefficients in three phase composite piezoelectric polymers Composites A 43 1612-9
[24] Carponcin D, Dantras E, Dandurand J, Aridon G, Levallois F, Cadiergues L and Lacabanne C 2014 Electrical and piezoelectric behavior of polyamide/PZT/CNT multifunctional nanocomposites Adv. Eng. Mater. 16 1018-25

[25] Saber N, Araby S, Meng Q, Hsu H-Y, Yan C, Azari S, Lee S-H, Xu Y, Ma J and Yu S 2014 Superior piezoelectric composite films: taking advantage of carbon nanomaterials Nanotechnology 25 1-10

[26] Carponcin D, Dantras E, Michon G, Dandurand J, Aridon G, Levallois F, Cadiergues L and Lacabanne C 2015 New hybrid polymer nanocomposites for passive vibration damping by incorporation of carbon nanotubes and lead zirconate titanate particles J. Non Cryst. Solids $40920-6$

[27] Wang Z, Wang H, Zhao W and Kimura H 2017 Epoxy-based composites embedded with high performance BZT-0.5BCT piezoelectric nanoparticles powders for damping vibration absorber application Crystals 7105

[28] Mekala N R, Schmidt R and Schröder K U 2018 Modelling and analysis of piezolaminated functionally graded polymer composite structures reinforced with graphene nanoplatelets under strong electroelastic fields Appl. Mech. Mater. 875 3-8

[29] Zhang C, Sheng J F, Ma C A and Sumita M 2005 Electrical and damping behaviors of $\mathrm{CPE} / \mathrm{BaTiO} 3 / \mathrm{VGCF}$ composites Mater. Lett. 59 3648-51

[30] Liu X, Chuanxi X, Huajun S, Lijie D, Rui L and Yang L 2005 Characterization of PZT/PVC composites added with carbon black J. Wuhan Univ. Technol. Mater. Sci. Ed. 20 60-4

[31] David C, Capsal J F, Laffont L, Dantras E and Lacabanne C 2012 Piezoelectric properties of polyamide $11 / \mathrm{NaNbO}_{3}$ nanowire composites J. Phys. D: Appl. Phys. 45 1-7

[32] Bessaguet C, Dantras E, Lacabanne C, Chevalier M and Michon G 2017 Piezoelectric and mechanical behavior of $\mathrm{NaNbO}_{3} / \mathrm{PEKK}$ lead-free nanocomposites J. Non Cryst. Solids 459 83-7

[33] Piollet E, Fotsing E R, Ross A and Michon G 2019 High damping and nonlinear vibration of sandwich beams with entangled cross-linked fibres as core material Composites B $168353-66$

[34] Kim H, Torres F, Wu Y, Villagran D, Lin Y and Tseng T L B 2017 Integrated 3D printing and corona poling process of PVDF piezoelectric films for pressure sensor application Smart Mater. Struct. 26085027

[35] Mahadeva S K, Berring J, Walus K and Stoeber B 2013 Effect of poling time and grid voltage on phase transition and piezoelectricity of poly(vinyledene fluoride) thin films using corona poling J. Phys. D: Appl. Phys. 46285305

[36] Waller D, Iqbal T and Safari A 1989 Poling of lead zirconate titanate ceramics and flexible piezoelectric composites by the corona discharge technique J. Am. Ceram. Soc. 72 322-4

[37] Sundar U, Cook-Chennault K A, Banerjee S and Refour E 2016 Dielectric and piezoelectric properties of percolative three-phase piezoelectric polymer composites $J$. Vac. Sci. Technol. B 34041232

[38] Lakes R S 2017 Viscoelastic Solids (1998) (Boca Raton, FL: CRC press)

[39] Piollet E, Poquillon D and Michon G 2016 Dynamic hysteresis modelling of entangled cross-linked fibres in shear J. Sound Vib. 383 248-64

[40] Latibari S T, Mehrali M, Mottahedin L, Fereidoon A and Metselaar H S C 2013 Investigation of interfacial damping nanotube-based composite Composites B 50 354-61

[41] Xiao X, Hiel C and Cardon A 1994 Characterization and modeling of nonlinear viscoelastic response of PEEK resin and PEEK composites Compos. Eng. 4 681-702 
[42] Barbier C, Dendievel R and Rodney D 2009 Role of friction in the mechanics of nonbonded fibrous materials Phys. Rev. E $801-5$

[43] Al-Bender F, Symens W, Swevers J and Van Brussel H 2004 Theoretical analysis of the dynamic behavior of hysteresis elements in mechanical systems Int. J. Non Linear Mech. 39 1721-35

[44] Bereaux Y 2004 Viscoélasticité Non-Linéaire Plasturgie de l'INSA-Lyon

[45] Quiroga Cortes L, Caussé N, Dantras E, Lonjon A and Lacabanne C 2016 Morphology and dynamical mechanical properties of poly ether ketone ketone (PEKK) with meta phenyl links J. Appl. Polym. Sci. 133133

[46] Bessaguet $C 2017$ Composite hybride à matrice polymère PEKK-niobate de sodium-graphène ou noir de carbone, pour un amortissement vibratoire passif par transduction-dissipation locale, à finalité aéronautique et spatiale PhD Thesis (France: Université Paul Sabatier)

[47] Marino L, Cicirello A and Hills D A 2019 Displacement transmissibility of a Coulomb friction oscillator subject to joined base-wall motion Nonlinear Dyn. 98 2595-612 